\title{
Regulatory Frameworks for the Successful Implementation of Construction and Demolition Waste Treatment Infrastructure
}

\author{
Sam Dowding \\ sam.dowding@mottmac.com \\ Mott MacDonald, Doha, Qatar \\ George Daoutis \\ george.daoutis@mottmac.com \\ Mott MacDonald, Doha, Qatar
}

\begin{abstract}
In an ever expanding world, our constant need to construct and to support a constantly growing population is resulting in significant increase in construction waste. Rapid expansion is a trend that can be seen throughout the Middle East therefore the need to manage the resulting construction waste should be seen as critical. According to the Qatar National Development Strategy (QNDS, 2018), construction waste was recorded at 3,796,540 tonnes per year in 2016 with a total of $11.5 \%$ successfully treated. The QNDS indicates that construction waste increase is expected to peak at approximately 6.6 million tonnes per annum by the year 2030 as a result of future development plans within the Qatar. A requirement exists to manage this material in a sustainable manner to minimise the quantities sent for final disposal at landfill sites which can be achieved through the treatment and reuse of the waste materials which arise form construction processes. This paper provides an overview of the methods considered suitable for the treatment of construction waste within the middle east region and describes in detail the regulatory frameworks that are typically required to support the successful implementation of construction waste treatment technology.
\end{abstract}

Keywords: Regulatory frameworks; Construction; Demolition

\section{INTRODUCTION}

Construction waste comprises the materials arising from the construction or demolition process. These materials are highly dependent upon the type of project being carried on. In the Middle East region, it is common to find significant quantities of concrete and other aggregate materials within the waste stream. These materials typically arise from temporary site structures, erroneous concrete works and temporary site roads. A typical construction waste composition is shown in Figure 1. Figure 1 shows that significant quantities of concrete and aggregate are expected to be present within the construction waste stream. These materials are suitable for recovering and restoring back to a usable aggregate and suitable for a variety of construction uses) (Globex-City Consult, 2001, National Development Strategy, 2018).

Processing the construction waste into a reusable recycled concrete aggregate requires a line of plant machinery designed to crush large pieces of waste concrete into specific grade aggregates whilst removing contaminated waste materials such as wood, plastic, metals, cement and sand. 

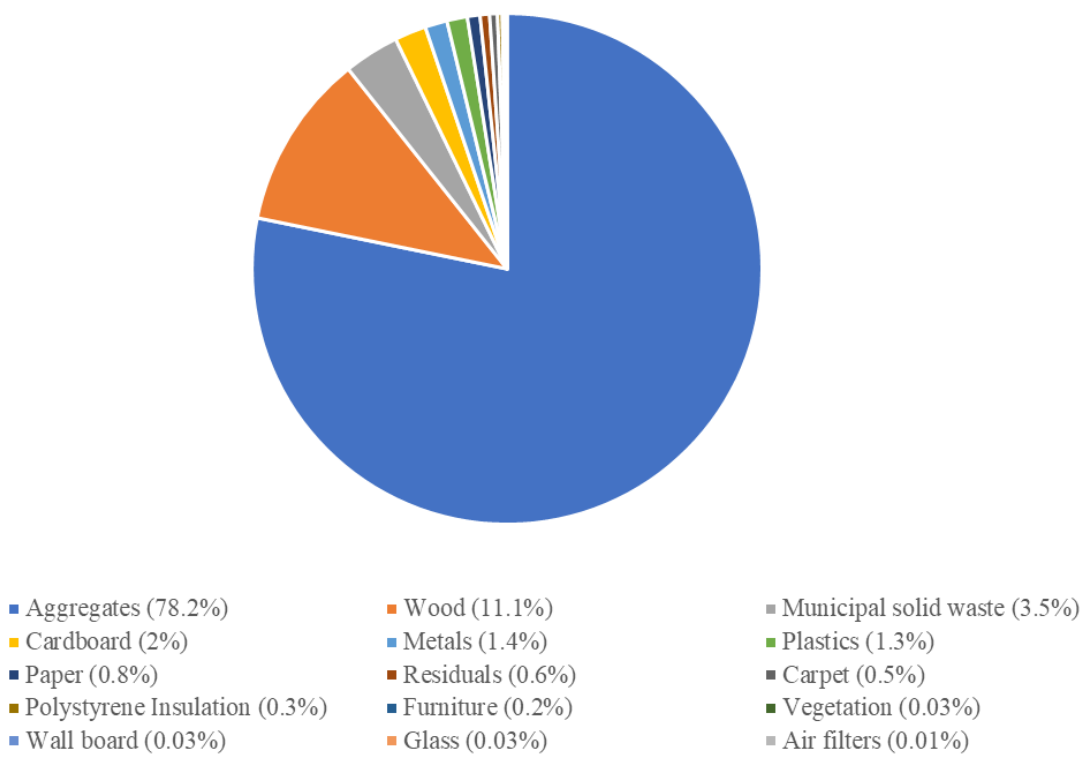

Figure 1: Construction waste composition

\section{RECYCLED CONCRETE AGGREGATES}

The aggregate material produced from a construction and demolition waste recycling facility is produced at a variety of different size grades suitable for use in various construction works. The potential uses include:

- Sub-base material under roads

- Drainage networks and standpipe filler

- Landscaping material

- Non load bearing concrete such as pavements and flooring

- Non load bearing concrete blocks

The quality of the output aggregate material is dependent upon the process used to remove contaminants from the input waste material. To reach a higher quality output product, washing is typically incorporated into the recycling process to remove sands and cement that can remain under a dry crushing system. A lower quality product can be used as a road sub-base material whilst a higher quality product can be used for landscaping works and non-load bearing concrete applications. Achieving a higher output quality is also dependent upon the quality of the input material that is received at the facility.

\section{REGULATORY FRAMEWORK}

\subsection{Input material}

Control of the input material arriving at the facility should be considered to maximise the throughput of potentially recyclable aggregates and increase the quality of the output aggregate product. Controls on the input material also prevent these recyclable materials from being disposed to landfill. Control of the input material is achieved by controlling the types of waste that arrive at the recycling facility and through the prevention of landfilling of concrete and aggregate waste. 


\subsubsection{Construction site controls}

A successful way of promoting the arrival of a cleaner concrete and aggregate waste material at the construction waste recycling facility is to promote source segregation at construction sites. Source segregation can be achieved through specific government regulations that require developers and construction contractors to segregate waste at the site with a focus on the segregation of concrete and aggregate wastes from other materials. Segregation on site should be followed by segregated transport of the waste to the construction waste recycling facility.

\subsubsection{Landfill charges}

A second way of promoting the segregation of concrete and aggregate wastes from other waste materials is to implement a higher landfill gate fee for mixed waste and a lower gate fee at the recycling facility for vehicles containing segregated concrete waste. With this regulation in place it is in the interest of the developer, construction contractor and delivery vehicle to make sure that only segregated concrete and aggregate are transported to the facility. Any mixed waste arriving at the gate is redirected to the landfill and charged a higher fee. A mixed material gate fee based on weight would be a successful way of reducing instances of mixing of construction waste with concrete. Concrete has a significantly heavier weight that other construction materials meaning weight based charges systems would be costly if the segregation requirements were not adhered to.

When a financial deterrent is put into place for the management of a waste stream, it is important to recognize that this act may result in increased instances of illegal dumping as delivery vehicles try to avoid the high mixed waste landfill charges by illegally disposing of the waste on unused remote ground. A system of fines and penalties enforced by the regulatory body can assist in the prevention of illegal dumping activities and should be seen as helpful when used in combination with a tiered gate fee system.

\subsection{Output product regulations}

The successful development of a construction and demolition waste recycling facility requires a demand for the output product that is produced. The demand for the output product can be increased through the development of product specifications which provide a guarantee to the quality of the product. Typically, different end use applications require the product to conform to different specifications which may indicate the quality, strength or grade of the product for its intended use. The requirement for a construction and demolition waste recycling facility to conform to various product specifications means the product can readily be used for a wider number of uses.

To support the product uses, regulatory mandates can be issued which require certain entities to enforce the use of a certain percentage of the recycled concrete aggregate for certain uses. An example of this is the use of the aggregate as a sub base material within road projects. The Abu Dhabi Waste Management Center has released a mandate which requires $40 \%$ of the total aggregate used in a road construction project to comprise recycled concrete aggregate. 


\section{CONCLUSION}

It can be seen that regulatory changes can have significant positive impact upon the success of construction and demolition of waste recycling facilities. These regulations are focused around either the input of concrete and aggregate material into the recycling facility or the output use of recycled aggregate in new construction projects.

\section{REFERENCES}

Globex-City Consult (2001). Construction waste composition - Abu Dhabi.

National Development Strategy (2018). Qatar Second National Development Strategy. 